\title{
A DEPRESSÃO ENTRE DOCENTES NO BRASIL: UMA REVISÃO DE LITERATURA
}

\section{ARTIGO DE REVISÃO}

SOUZA, Jeane Mendes Pinheiro de ${ }^{1}$

SOUZA, Jeane Mendes Pinheiro de. A depressão entre docentes no Brasil: uma revisão de literatura. Revista Científica Multidisciplinar Núcleo do Conhecimento. Ano 06, Ed. 06, Vol. 12, pp. 128-141. Junho de 2021. ISSN: 2448-0959, Link de acesso: https://www.nucleodoconhecimento.com.br/psicologia/depressao-entredocentes, DOI: 10.32749/nucleodoconhecimento.com.br/psicologia/depressao-entredocentes

\section{RESUMO}

$\mathrm{Na}$ atualidade, problemas de saúde que envolvem o estresse provocado pelo trabalho são uma realidade cada vez mais comum. Nesse contexto, há profissões e profissionais que são mais expostos e sujeitos a esses tipos de patologias, como os profissionais da educação. Estudos realizados em todo o mundo apontam que os educadores correm um grande risco de sofrer esgotamento físico e/ou mental, que envolvem as dificuldades materiais e psicológicas associadas ao exercício da atividade docente. Sabe-se que tais problemas de saúde comprometem enormemente a qualidade de vida desses profissionais e, dentre esses, destaca-se a depressão em suas manifestações que podem envolver melancolia e tristeza de várias formas e em vários níveis. O comprometimento da qualidade de vida desses profissionais faz com que, cada vez mais, seja necessário aprofundar pesquisas e abordagens que possam colaborar para que sejam encontradas alternativas que minimizem os efeitos desse mal. Devido ao exposto, esse trabalho tem por objetivo realizar estudo sobre a depressão e a sua ocorrência entre docentes. Como metodologia, foi realizada pesquisa bibliográfica com uma revisão sobre estudos e autores que aprofundem a abordagem dos assuntos depressão, depressão entre professores, melancolia e alternativas para o enfrentamento da depressão.

Palavras-Chave: Depressão, Qualidade de vida, Melancolia, Tristeza, Profissionais da Educação.

\footnotetext{
${ }_{1}^{1}$ Pós-Graduada em Terapia Cognitiva Comportamental pela UNINTER; Graduada em Psicologia pela Cesupi Faculdade de llhéus.
}

$\mathrm{RC}: 89183$

Disponível em: https://www.nucleodoconhecimento.com.br/psicologia/depressao-entre- 


\section{INTRODUÇÃO}

Em cada tempo, de acordo com a cultura e os costumes de cada sociedade, surgem novas doenças e patologias que acometem os indivíduos e os grupos sociais. Isso ocorre devido ao caráter de que se reveste o comportamento e as cobranças a que estão sujeitas as pessoas, o que se deve aos valores e às necessidades que são postos em evidência em cada época. Assim, mesmo profissões que possuem uma longa história, reconhecidas pela sua importância, são passíveis de serem atingidas pelos reflexos de mudanças de valores e de comportamento.

Dessa forma, encontra-se como uma realidade atual a grande incidência de casos de depressão na sociedade como um todo e, mais especificamente, entre profissões que demandam um grande esforço, devido ao estresse que representam, como a docência. Sabe-se haver uma grande incidência de depressão entre professores, uma doença vista como o mal do século e a quarta causa mundial de adoecimento e que atinge pessoas das mais variadas culturas, faixas etárias e classes sociais (AROS, 2008).

Uma das causas da depressão entre docentes é que o trabalho é realizado em ambientes conflituosos com uma alta carga de exigências de trabalho, dentre as quais se destacam as muitas tarefas extraclasse, reuniões e atividades adicionais. Além disso, são muito comuns problemas com alunos que podem chegar a ameaças e a agressões verbais e físicas. Essa realidade estressante impacta na saúde física e mental e no desempenho profissional dos professores (CAPEL, 1987).

É importante destacar que, nesse contexto, quando ocorre de o docente adoecer, a escola tem prejudicada a sua função social que acaba por não se concretizar. Assim, a formação de cidadãos e a construção de uma autonomia e de uma consciência de cidadania ficam comprometidas. A depressão em seus mais variados graus tem sido considerada uma das doenças que fazem parte do quadro da Síndrome do Esgotamento Profissional (Burnout) (MINISTÉRIO DA SAÚDE, 2001).

Considerando-se a importância do problema e a necessidade de que discutidos os aspectos mais relevantes sobre o assunto, esse trabalho tem por objetivo realizar estudo sobre a depressão e a sua ocorrência entre docentes. Como metodologia, foi realizada pesquisa bibliográfica com uma revisão sobre estudos e autores que aprofundem a abordagem dos assuntos depressão, depressão entre professores, melancolia, tristeza e alternativas para o enfrentamento da depressão.

RC: 89183

Disponível em: https://www.nucleodoconhecimento.com.br/psicologia/depressao-entre- 


\section{A DEPRESSÃO}

De acordo com a Organização Mundial da Saúde (OMS, 2002) depressão é um transtorno mental comum, que tem como características "tristeza, perda de interesse, ausência de prazer, oscilações entre sentimento de culpa e baixa autoestima, além de distúrbios do sono ou do apetite" e "sensação de cansaço e falta de concentração". Destaca-se que o grau de incapacitação creditado aos transtornos depressivos demonstra-se maior do que em outras doenças crônicas de caráter físico, como hipertensão, diabete melito ou artrite.

São apontadas como tipos de depressão as acidentais ou reacionais que têm como motivação algo que possa ter modificado ou transformado de alguma forma a vida de uma pessoa. Já o que se convenciona chamar de vida depressiva ocorre quando a depressão é permanente, o que pode ser visto nas pessoas que demonstram sempre um sentimento de desconforto. Nesse caso, os poucos momentos em que estão bem são passageiros, não constituindo-se como uma base sólida para a vida (TATOSSIAN, 2012).

Na depressão há manifestações diversas que configuram esse problema. A tristeza pode ser considerada como um sintoma dos quadros depressivos e expressa uma manifestação exterior de problemas decorrentes do psiquismo. Esse tipo de manifestação não é especialmente destacada, pois tem na sua relevância o grau de ocorrência e permanência que varia bastante. No entanto, pode comprometer a qualidade de vida, quando ocorre com frequência (FUCHS, 2013).

No que diz respeito à melancolia, diferencia-se da tristeza devido aos diferentes níveis que elas ocupam na vida psíquica do sujeito. A melancolia "é caracterizada como um distúrbio da ordem do humor e não do sentimento, como a tristeza. o sentimento é uma ação, um movimento afetivo e, portanto, possui direção a qualquer coisa ou a alguém" (TATOSSIAN, 2012).

\subsection{MELANCOLIA: UMA FORMA DE DEPRESSÃO}

Utiliza-se o termo melancolia, de acordo com o Manual Diagnóstico e Estatístico de Transtornos Mentais (DSM IV), para determinar um subtipo de depressão.

Diferentemente de outras formas do mal, a depressão melancólica pode ter como fator determinante aspectos genéticos seriam os principais determinantes.

Destacam-se nesse tipo de depressão alterações psicomotoras (LAFER et al.,1996).

De acordo com Tatossian (2006, p. 113), a depressão melancólica ocorre quando há, nas palavra do autor, "uma experiência de emurchecimento e de definhamento

RC: 89183

Disponível em: https://www.nucleodoconhecimento.com.br/psicologia/depressao-entre- 
do vivido, da perda do frescor". O sentimento de melancolia é responsável por um sofrimento devido ao isolamento vivenciado pelo sujeito. Nesse contexto, é importante diferenciar o sofrimento normal de um sofrimento melancólico, pois a melancolia causa mais do que pode-se expressar com episódios de tristeza, que são apenas uma das formas de expressão da melancolia.

Contemporaneamente, a melancolia manifesta-se como uma das formas de depressão, tendo em sua causa uma disfunção neuroquímica que pode ser corrigida pela ação dos psicofármacos. Segundo Freud, o termo melancolia seria utilizado como referência a um estado depressivo mais intenso, mais grave, no qual se acrescentavam diversos elementos. A palavra melancolia seria usada para definir um quadro com predomínio de afetos depressivos intensos (DELOUYA, 2002, p. 22).

\subsection{TRISTEZA E DEPRESSÃO}

A tristeza e a depressão são muito comumente confundidas, no entanto, diferenciam-se, pois existe uma eventualidade relacionada à tristeza, já a depressão ocorre em um contexto de uma determinada constância dessa tristeza. "A tristeza faz parte da condição humana, assim como vários outros sentimentos. Pode-se ficar chateado porque naquele dia não houve produção do que se queria, ou ainda devido a uma discussão, mas a tristeza passa". Por outro lado, quando se trata de depressão, existe um envolvimento ou comprometimento maior de outras áreas, como comportamento, psicomotricidade, expressão do pensamento e da chamada neurovegetativa, ligada ao sono e à alimentação. Quando se trata do diagnóstico de depressão, busca-se dois sintomas básicos: "o que se denomina humor deprimido, que é essa tristeza, desesperança, vazio, angústia, às vezes choro, até uma irritabilidade; e a perda ou diminuição do interesse ou prazer pelas coisas da vida" (SENE-COSTA, 2011, p. 37).

\section{A DEPRESSÃO ENTRE PROFESSORES}

Segundo a Organização Internacional do Trabalho (OIT), a função do professor na sociedade é essencial à formação do cidadão para a vida. Devido ao caráter de seu trabalho, esses profissionais têm sobre si uma grande responsabilidade, mas, por outro lado, não existem condições de trabalho ideias que possam contribuir para a segurança e a saúde desses profissionais (OIT, 1984).

Dentre os problemas de saúde que têm afetado determinantemente esses profissionais, destaca-se a depressão. Destacam-se, dentre os fatores que contribuem para o surgimento desse problema, "excesso de trabalho, indisciplina em

RC: 89183

Disponível em: https://www.nucleodoconhecimento.com.br/psicologia/depressao-entre- 
sala de aula, salário baixo, violência, demandas de pais de alunos, bombardeio de informações, desgaste físico e, principalmente, a falta de reconhecimento de sua atividade" (GASPARINI et al., 2005).

Essas informações são corroboradas por pesquisas que comprovam essas ocorrências, como a que segue, no relato de D'Agostini (2019):

De acordo com pesquisa da Organização para a Cooperação e Desenvolvimento Econômico (OCDE) com mais de 100 mil professores e diretores de escolas do segundo ciclo de ensino fundamental revela que o Brasil é o país que tem o maior índice de violência contra professores. A enquete foi feita com 34 países e constatou que $12,5 \%$ dos professores brasileiros já foram vítimas de agressões verbais ou intimidação de alunos pelo menos uma vez na semana (D'AGOSTINI, 2019).

Quando consideradas as condições de trabalho, as circunstâncias nas quais os docentes têm de utilizar suas capacidades físicas, cognitivas e afetivas com o objetivo de atuar na formação de pessoas, essa responsabilidade pode levar a um esforço muito superior ao que deveria ser empregado pelo docente, o que desencadeia um estresse, grande causador de depressão (GASPARINI, 2005).

\subsection{CONTEXTO E CAUSAS}

$\mathrm{Na}$ atualidade, o papel que o professor desempenha vai além do que se espera na mediação do processo de conhecimento do aluno. A atuação do professor ultrapassou os limites da sala de aula para que fosse possível estabelecer uma comunicação entre a escola e a comunidade escolar. Dessa forma, o professor, além de ensinar, é responsável por participar da gestão e do planejamento escolares. Assim, precisa dedicar-se mais, incluindo em suas responsabilidades as famílias e a comunidade.

A complexidade das tarefas de que devem dar conta os professores faz com que necessitem, muitas vezes, meios de requalificação e tempo para que os conhecimentos necessários sejam adquiridos. Assim, os educadores acabam tendo de buscar por si próprios alternativas que se traduzem em aumento não reconhecido e não remunerado da jornada de trabalho (OLIVEIRA, 2003).

Estudo realizado em várias localidades, como Belo Horizonte e Montes Claros (MG), Vitória da Conquista e Salvador (BA), Santa Maria (RS) e Campinas (SP), dentre outras, com o objetivo de verificar as condições de saúde do professor, apontaram uma grande incidência de pedidos de licença médica e suas motivações. Foram

RC: 89183

Disponível em: https://www.nucleodoconhecimento.com.br/psicologia/depressao-entre- 
apontados como motivações, aspectos relacionados às condições de trabalho: dentre outros, "excesso de tarefas e ruídos, pressão por requalificação profissional, falta de apoio institucional e de docentes em número necessário". O estudo ainda aponta que tais problemas "geram um sobre-esforço na realização de suas tarefas". As conclusões demonstram que "os resultados aferidos nas diversas cidades são convergentes e que os professores estão mais sujeitos que outros grupos a terem transtornos psíquicos de intensidade variada" (CURI, 2010).

Os profissionais da educação se sentem pressionados Muitos desses elementos de pressão são fruto de uma reconfiguração do mundo do trabalho, que não foi realizada a contento no que diz respeito a suprir as necessidades do professor na mesma escala em que é cobrado. O sistema escolar transfere ao profissional a responsabilidade por cobrir as lacunas existentes na instituição, a qual estabelece mecanismos rígidos e redundantes de avaliação profissional, diz Sandra Gasparini (CURI, 2010).

Devido à desvalorização da carreira docente, houve um aumento expressivo dos problemas psíquicos entre professores devido à mudança de valores e ao crescimento do apelo ao consumo e a valorização do ter em detrimento do ser. Em pesquisa de 2003, realizada pelo Sindicato dos Professores do Ensino Oficial do Estado de São Paulo (Apeoesp) foi apontado um percentual de " $46 \%$ dos professores que já tiveram diagnosticado algum tipo de estresse, chegando a um percentual de $51 \%$ entre as mulheres (CURI, 2010).

De acordo com a Confederação Nacional dos Trabalhadores em Educação (CNTE), no Mato Grosso do Sul, "mais de $60 \%$ das licenças médicas concedidas aos trabalhadores em educação no Estado são para professores. Do total de licenças, $38 \%$ estão relacionadas a transtornos mentais e comportamentais, o principal motivo dos afastamentos" (CURI, 2010).

Outro motivo de estresse para os docentes é o medo constante de perderem o emprego, entre os professores de instituições privadas: em algumas (instituições), os alunos fazem um motim contra o professor e a escola prefere demitir o profissional, mesmo sem um real motivo. Já nas escolas públicas, a constante pressão por números que indiquem altos percentuais de aprovação, devido à avaliação de desempenho e à meritocracia adotada pelas administrações de algumas cidades e estados, é imposta uma pressão aos professores. Essa insegurança pode contribuir determinantemente para a depressão entre os docentes, o que pode ocorrer, tanto entre profissionais que atuam nas escolas públicas, quanto entre professores da rede particular de ensino (CURI, 2010).

RC: 89183

Disponível em: https://www.nucleodoconhecimento.com.br/psicologia/depressao-entre- 


\subsection{EFEITOS E CONSEQUÊNCIAS}

O estresse e a depressão relacionados a eventos durante as rotinas de trabalho são comuns para os profissionais da educação. Exemplos disso são as ocorrências após episódios de violência contra educadores. Pode-se mencionar as ocorrências em 2018 registradas na Secretaria Municipal de Educação no município do Rio de Janeiro que "emitiu 3.055 licenças por doenças relacionadas ao estresse e à depressão", onde "um professor é licenciado a cada três horas por doenças ligadas ao estresse" (D'AGOSTINI, 2019).

A violência escolar pode provocar impactos na saúde que podem levar a um quadro de efeitos mais prolongados, como a depressão, mas também podem surgir do próprio quadro depressivo já preexistente. São considerados como os principais impactos da violência escolar à saúde "sintomas psicossomáticos como dores de cabeça, tontura, náusea, diarreia, enurese, sudorese, taquicardia, dores musculares, alterações no sono (insônia ou sono excessivo)"; consequências do "'estresse que pode aumentar a vulnerabilidade a doenças diminuindo a resistência imunológica; problemas psicológicos "como ansiedade, medo, raiva, irritabilidade, inquietação, cansaço, insegurança, isolamento, impotência, rejeição, tristeza, angústia, baixa autoestima, depressão e pensamentos suicidas, dentre outros; problemas de socialização, com o aumento do "isolamento social, gerando insegurança que pode afetar a confiança no outro, a capacidade de se expressar em público, de resolver conflitos e tomar decisões" (D'AGOSTINI, 2019).

\subsection{CAMINHOS E ALTERNATIVAS PARA O ENFRENTAMENTO DA DEPRESSÃO}

De acordo com os profissionais de saúde envolvidos no tratamento da depressão, há alternativas e caminhos que diferem, o que depende do grau de desgaste e profundidade do quadro de depressão. É possível, em alguns casos, que a pessoa possa passar somente por psicoterapia; possa ser medicada temporariamente com ansiolítico ou antidepressivo, concomitantemente à psicoterapia e, às vezes, há casos em que o profissional precisa ser deslocado para uma função burocrática ou tenha de trabalhar com outro perfil de alunos (D'AGOSTINI, 2019).

É importante destacar que existem projetos que podem ser adotados por escolas e redes de ensino, como o implementado em uma escola de Ribeirão Preto, SP, que teve como objetivo "desenvolver autoestima, tolerância e cooperação entre estudantes". O projeto foi adotado devido à escola apresentar um "alto índice de violência no local e às dificuldades no processo de ensino-aprendizagem". A ideia

RC: 89183

Disponível em: https://www.nucleodoconhecimento.com.br/psicologia/depressao-entre- 
é "adotar medidas preventivas contra a violência, que, embora sejam focadas nos alunos, impactam o clima escolar como um todo e promovem de maneira positiva mais saúde mental nas instituições de ensino" (D'AGOSTINI, 2019).

Também outras ações que podem ser efetivas passam pela reflexão "sobre os fatores que levam ao estado depressivo de professores através das narrativas dos próprios indivíduos. Isso torna possível compreender "como o docente vivencia a doença, quais suas expectativas quanto à superação do problema e principalmente e como a docência é ressignificada pós-afastamento". Essa compreensão torna possível o desenvolvimento de programas para "identificar, atender e tratar profissionais acometidos pela depressão, bem como auxiliar gestores e profissionais da educação a identificar os sinais do corpo, sintomas e comportamentos característicos da doença" (SOUZA e SOUZA, 2015, p. 182).

Ao compartilhar vivências e ter contato com outras narrativas, o profissional de educação pode repensar sua trajetória, o que pode evitar um afastamento da profissão. Também pode-se analisar as causas do estresse na docência, tornando possível aos educadores "enxergar quais os problemas que contribuem com o adoecimento em sua profissão e como minimizar esses problemas" (SOUZA e SOUZA, 2015, p. 182).

\subsection{PROPOSTAS DE AÇÕES A SEREM ADOTADAS}

Sugere-se adotar um animalzinho de estimação como uma forma de enfrentar o efeitos da depressão. Com a relação que se estabelece devido à interação que se faz necessária e que ocorre também de forma espontânea, é preciso realizar atividades que elevam os níveis de serotonina e dopamina, que estão ligados à sensação de bem-estar. A atenção e os cuidados que são incentivados pela vontade de promover bem-estar ao bichinho fazem com que, de forma natural, ocorram atividades físicas, como passear ou brincar, que liberam endorfinas que aliviam os sintomas da doença. De acordo com especialistas, a proximidade de um animalzinho de estimação pode afastar pensamentos negativos e diminuir a angústia, a tristeza e a solidão (REED et al., 2012).

A depressão pelo seu caráter de inatividade pode e deve ser enfrentada por atividades que estimulem quem sofre desse mal. Dessa forma, a dança pode atuar para a redução dos sintomas de depressão e ansiedade. Dançar faz com que possa ocorrer a expressão de sentimentos e o aprimoramento de uma autopercepção sobre as emoções, o que também poderá colaborar para o bem-estar físico e social das pessoas que sofrem desse mal. Sabe-se também que a dança pode ter efeitos positivos no humor, além de uma melhora na capacidade aeróbica, na flexibilidade e na capacidade de percepção sobre o corpo, o que pode levar a uma melhora na

RC: 89183

Disponível em: https://www.nucleodoconhecimento.com.br/psicologia/depressao-entre- 
autoestima que, normalmente, fica prejudica devido à depressão. Dançar aprimora o autoconhecimento e estimula a valorização do próprio corpo e da capacidade que ele demonstra de expressão (SILVA, 2015).

Outra atitude a adotar é o resgate da percepção de prazer nas coisas e momentos simples do cotidiano. A ideia é que se possa perceber o sentido e o prazer em ações, eventos e ocorrências do cotidiano para que se possa também valorizar o que de maior também ocorre. Deve-se passar a observar o que existe de belo e que desperte essa percepção de cada um e que pode em muito variar, flores, momentos do dia (nascer ou pôr do sol), o gosto de uma comida, em pequenas abstrações que funcionarão de forma diferente para cada um, mas que terão o mesmo efeito. A ideia, para quem já apresenta um quadro depressivo, é "reaprender a focar no que não se consegue perceber devido à doença" (GAUER, 1997).

Outra medida a ser adotada é ocupar-se com atividades que proporcionem prazer, o que também pode variar muito, dependendo de cada pessoa. para quem já apresenta depressão, deve-se "recomeçar a realizar atividades que um dia já foram divertidas". Importa determinar, no entanto, o que desperta o interesse no momento, o que pode ter mudado. Se necessário, deve-se buscar novas formas de diversão. Isso pode ser estimulado pelas pessoas com as quais quem sofre de depressão convive ou por ela mesmo, sem desistir de buscar alguma atividade que seja prazerosa, mesmo que isso não funcione em alguns momentos. É importante buscar "novidades, aprender coisas novas e prazerosas", o que evita o insucesso das ações (GAUER, 1997).

Outra medida essencial para pessoas que sofrem de depressão é o sono equilibrado e saudável porque, normalmente, essas pessoas dormem demais ou não conseguem pegar no sono. Segundo os especialistas isso se deve "a alterações nos níveis de serotonina e noradrenalina, hormônios que regulam o sono. Uma vez que "o sono é essencial para o cérebro regular novamente esses hormônios e amenizar os efeitos da depressão", ele deve ocorrer em equilíbrio, sem exagero ou ausência. Para quem tem falta de sono, indicam-se exercícios de respiração para o relaxamento e facilitação no momento de adormecer. Caso a pessoa durma demais, indica-se que seja despertada e estimulada de alguma forma para que não durma excessivamente (GAUER, 1997).

\section{CONSIDERAÇÕES FINAIS}

Observa-se como uma realidade da sociedade contemporânea que os professores demonstram ter uma propensão maior ao sofrimento psíquico dentre os quais se destaca a depressão em seus estágios ou escala de gravidade. Ao analisar as

RC: 89183

Disponível em: https://www.nucleodoconhecimento.com.br/psicologia/depressao-entre- 
relações entre saúde e trabalho é possível perceber as associações entre os problemas identificados e as condições e características do trabalho descritas.

Os profissionais da educação, sendo expostos a níveis elevados de estresse, o que ocorre por diferentes motivos, acabam vitimados por depressão que surge de variadas formas e pode atingir níveis que acabam levando o profissional ao afastamento do trabalho, sem que haja o entendimento do que o motiva, sem o qual pode-se tornar impossível o retorno do profissional a desempenhar a profissão para o qual foi formado e única com a qual, muitas vezes, tem experiência.

Muitos profissionais da educação veem-se desmotivados para o trabalho, mas não tem alternativa a não ser continuar, pois necessitam dele para seu sustento. $\mathrm{A}$ grande maioria não pode perder o tempo investido em sua formação e as experiências profissionais únicas amealhadas ao longo de uma carreira profissional e continuam, mesmo sem que haja condições mínimas para a realização do trabalho. Isso ocorre em prejuízo de todos: dos profissionais e da sociedade como um todo.

Assim, é fundamental que haja valorização dos profissionais e o acolhimento das instituições que devem ouvir e propiciar momentos para que os profissionais possam expressar seus receios, descontentamentos e sentimentos. Deve-se oferecer aos profissionais da educação alternativas de abordagem para quem já está doente e de profilaxia para quem pode vir a adoecer. Sabe-se que deve haver tratamento para quem já se encontra em depressão, mas a reintegração desses profissionais passa pela necessidade de que sejam acolhidos, ouvidos e orientados.

\section{REFERÊNCIAS}

AROS, M.S. Produção científica sobre depressão: Análises de resumos. Campinas, SP. Universidade Católica de Campinas, 2008.

\section{CAPEL, S.A. The incidence of and influences on stress and burnout in secondary school teachers. Br J Educ Psychol 1987; 57:279-88.}

CARLOTTO, M.S. Burnout e o trabalho docente: considerações sobre a intervenção. Revista Eletrônica InterAção Psy 2003; 1:12-8.

CURI, F. O professor brasileiro está doente. Revista Educação - Edição 119, 2010. Disponível em: <http://stellabortoni.com.br/index.php/artigos/1177-o-paofissoabaasiliiao-ista-ioioti>. Acesso em: 17 de Jan. de 2021.

RC: 89183

Disponível em: https://www.nucleodoconhecimento.com.br/psicologia/depressao-entre- 
D'AGOSTINI, A. C. Brasil lidera índice de violência contra professores: o que podemos fazer? Nova Escola, Junho/2019. Disponível em:< https://novaescola.org.br/ conteudo/17609/brasil-lidera-indice-de-violencia-contraprofessores-o-que-podemos-fazer>. Acesso em: 10 de jan. de 2021.

DELOUYA, D. Depressão estação psique. São Paulo: Escuta - Fapesp, 2002.

FUCHS, T. Depression, intercorporeality, and interaffectivity. Journal of Consciousness Studies, 20(7-8), 219-38, 2013.

GASPARINI, S. M.; BARRETO, S. M.; ASSUNÇÃO, A. A. O professor, as condições de trabalho e os efeitos sobre sua saúde. Educ. Pesqui. São Paulo, v. 31, n. 2, p. 189-199, Ago. 2005. Disponível em: <http://www.scielo.br/scielo.

php?script=sci_arttext\&pid=S151797022005000200003\&lng=en\&nrm=iso $>$. Accesso em: 19 Jan. 2021.

GAUER, G. et al. Terapias alternativas: uma questão contemporânea em psicologia. Psicol. cienc. prof., Brasília, v. 17, n. 2, p. 21-32, 1997. Disponível em:<http://pepsic.bvsalud.org/scielo.php?script=sci_arttext\&pid=S141498931997000 200004\&lng=pt\&nrm=iso >. Acesso em: 18 de jan. 2021.

LAFER, B.; NIERENBERG, A. A.; ROSENBAUM, J. F.; FAVA, M. Outpatients with DSM-III-R versus DSM IV Melancholic Depression. Comprehensive Psychiatry 1996;37(1):37-9.

MINISTÉRIO DA SAÚDE. Doenças relacionadas ao trabalho: manual de procedimentos para os serviços de saúde. Brasília: Ministério da Saúde, 2001.

MOREIRA, A. G. C. Clínica da melancolia. São Paulo: Escuta - Edufpa, 2002.

OLIVEIRA, D. A. As reformas educacionais e suas repercussões sobre o trabalho docente. In Reformas educacionais na América Latina e os trabalhadores docentes. Autêntica: Belo Horizonte, 2003, p. 13-35.

ORGANIZAÇÃO INTERNACIONAL DO TRABALHO. A condição dos professores: recomendação Internacional de 1966, um instrumento para a melhoria da condição dos professores. Genebra: OIT/ Unesco, 1984.

ORGANIZAÇÃO MUNDIAL DA SAÚDE (OMS). Relatório Mundial de Saúde. Lisboa: Climepsi Editores, 2002. 
REED, R.; FERRER, L.; VILLEGAS, N. Curadores naturais: uma revisão da terapia e atividades assistidas por animais como tratamento complementar de doenças crônicas. Rev. Latino-Am. Enfermagem. maio-jun. 2012.

SENE-COSTA, Elizabeth. As emoções e os transtornos depressivos. O teatro do perdão como palco de resgates. Rev. bras. psicodrama, São Paulo, v. 19, n. 2, p. 85-99, 2011.Disponível em: <http://pepsic.bvsalud.org/scielo.php?script=sci_arttext\& pid=S010453932011000200008\&lng=pt\&nrm=iso >. Acesso em: 02 jan. 2021.

SILVA, V. A. Benefícios afetivo-sociais da prática da dança para estudantes dos Núcleos de Arte da Prefeitura do Rio de Janeiro. Tese de Doutoramento.

Faculdade de Motricidade Humana, Universidade de Lisboa, 2015.

SOUZA, E. C. Conte sua história: doença, crônica, narrativas e reconstrução biográfica. Curitiba: CRV, 2016.

TATOSSIAN, A. A fenomenologia das psicoses. São Paulo, SP: Escuta, 2006.

TATOSSIAN, A. Fenomenologia da depressão. In TATOSSIAN, A.; MOREIRA, V. Clínica do Lebenswelt: Psicoterapia e psicopatologia fenomenológica. São Paulo, SP: Escuta, 2012.

[1]

Enviado: Março, 2021.

Aprovado: Junho, 2021.

RC: 89183

Disponível em: https://www.nucleodoconhecimento.com.br/psicologia/depressao-entre- 